\title{
Chapter 2.
}

\section{Reputation management in Nordic universities - profiles and development over time}

Tom Christensen, Department of Political Science, University of Oslo

Åse Gornitzka, Department of Political Science, University of Oslo

\section{Introduction}

The focus in this chapter is on reputation management and its development in Nordic universities, which mostly are public universities. This development could be seen based on two sets of factors. First, the more general development of public reforms in these countries, which has some typical and tension-ridden elements (Greve, Lægreid \& Rykkja, 2016). The Nordic countries are overall similar in the way that they constitute a so-called Nordic model, which encompasses scoring high on a large well-fare state, Rechtsstaat values, equality, scepticism towards privatization in the public sector, close collaboration between employers' and employees' organizations, etc. But at the same time, the Nordic countries show variety in implementing a hybrid mix of New Public Management (NPM) and post-NPM reforms, with Sweden most favouring NPM reforms.

The second development features relates to the whether Nordic universities overall will follow the European trend of imitating, with some adaptations, main features of modern American universities and both focus on reputation management and social embeddedness. The Nordic countries have a distinctive history when it comes to reforms and change in the areas of institutional autonomy and public funding of universities. The 'rethinking' of the role of the state in public sector governance started in the 1970s and 1980s (Gornitzka \& Maassen, 2000). Yet none of the Nordic countries initiated major reforms of university autonomy or higher education funding before the 1990s. Since then, however, they have been influenced by what can be identified as the 'global script' on modern university governance, reflected in increased formal institutional and financial autonomy and in a focus on economic aspects of universities, as well as the more recent instruments to boost 'world class universities' (Christensen et al., 2014). The performance-based orientation has become paramount.

The main questions to be answered in this chapter is:

- What is typical for the reputation management of the Nordic universities, as reflected by their websites? How do they balance the core symbols related to performance, moral and professional qualities? 
- How does the reputation management of the Nordic universities change over time concerning convergence or divergence?

- How could the main features of reputation management be explained, based on the main perspectives outlined in chapter 1 ?

The empirical data used to answer these questions are based on a web census, a study of the websites of twenty universities in four Nordic countries during the month of April 2015, compared with the websites in the same month in 2005 (cf. the method section in chapter 1).

We start by outlining the context of Nordic universities and formulate some expectations. After reporting the main results, we move on to a discussion section that is based on the theory outlined in chapter 1 . Our conclusion considers the theoretical and empirical implications of our study.

\section{Method.}

The empirical data used to answer these questions are based on a web census, a study of the websites of twenty universities in four Nordic countries during the month of April 2015, compared with data from 2005 drawn from the websites from a subsample of three of the five universities in each of the three Nordic countries (cf. the method section in chapter 1). The cases that make up the subsample for comparison across time comprise the two large, general comprehensive universities and one specialized university per country, i.e. in total 3 cases per each of the Nordic countries. The reasons for this selection were that we wanted to include data that would allow us to compare reputation management across time to detect patterns of convergence or divergence. Some of the case institutions in 2015 have been established only after 2005 and some are not covered by the data base on historic websites (Wayback machine) and hence these institutions had to be excluded from sub-sample. In order to respect the symmetry of the each of the Nordic cases, the data from 2005 only contain websites from the three types of universities described above, in total 12 universities make up the subsample where we can see change patterns over a ten year period.

We start by expanding on the contexts of universities' reputation management. We then report the main results starting with the overall profile of reputation management as they appear in the 2015 data set before we identify the main changes in reputation management and patterns of divergence and convergence over time. We then move on to a discussion section. Our conclusion considers the theoretical and empirical implications of our study. 


\section{Context of Nordic universities and expectations.}

Among the key defining characteristics of the Nordic socio-economic model is public investment in the knowledge sector. ${ }^{1}$ Educational attainment and spending per capita in the Nordic countries is generally high. With around fifty universities and over a hundred other types of higher education institutions, the Nordic countries have well-developed higher education systems. Seven universities are among the top hundred universities in the so-called Shanghai ranking. ${ }^{2}$ In terms of top universities per capita, no other region outperforms the Nordic countries.

The Nordic countries also share some characteristics of state steering of higher education institutions rooted in the idea that higher education institutions are instruments for national policy goals and part of a national public system. This is especially visible in the high level of public funding for university education and research and the clear emphasis on access to higher education. Participation rates in higher education now range from 50 percent in Denmark and 60 percent in Sweden and Norway to Finland's 65-70 percent (Gornitzka \& Maassen, 2011). None of the Nordic countries studied have introduced tuition fees for national students in public institutions, but three out of four have introduced fees for students from outside the EU/EEA (Norden, 2013). Student support systems are universalistic, geared towards students' welfare state entitlement rather than parental responsibility or private investment in human capital (Jungblut, 2015). Hence public authorities are the primary source of funding for higher education institutions. Danish, Finnish and Norwegian universities receive on average around 65 percent of their funding from the state. ${ }^{3}$

In terms of the formal status of universities the Nordic systems have taken different reform routes. Since 2003, Danish universities have had the status of self-owned institutions. Finnish universities are also self-owned public institutions, with the exception of two universities that opted for a status as private foundations. The recently established Aalto University is one of them. Swedish and Norwegian universities have not changed their status as public institutions. Sweden's universities include some private institutions (e.g. Chalmers University), but the proposal to change the status of universities met with massive opposition and the process was stopped when the current social democratic government took office.

\footnotetext{
${ }^{1}$ World Bank Knowledge Economy Index, Ranking 2012, http://siteresources.worldbank.org/ INTUNIKAM/ Resources/2012.pdf

${ }^{2}$ See: http://www.shanghairanking.com/ARWU2012.html

${ }^{3}$ Swedish universities receive research funding from national research councils and foundations and not directly from state budgets, making the percentage of basic public funding more complicated to calculate.
} 
In the case of Denmark, Sweden and Finland, universities' research performance is included in a system of contracts negotiated between institutions and state authorities, whereas Norwegian universities are part of a state sector system of goal and performance management. This implies that performance information in this sector is systematically gathered nationally for key parameters in research and education. In addition, the global or European-wide university rankings have become (an ambiguous) part of the policy discourse in the Nordic countries - where policy-makers practice an 'inverse' decoupling of talk and action (Gornitzka, 2013).

In chapter 1, we discussed arguments for convergence or divergence concerning reputation management in universities, since we both have different universities in different countries and development over time. Convergence can be seen connected to global fashions (cf. Cziarnawska \& Sevon, 1996), while divergence may relate to different tasks and functions (Morphew \& Harley, 2006). Arguments for a mixed position could be that national profile reflect and filter global trends (Bleiklie et al., 2011) or more generally that the influence of global logics is uneven because of diversity in actor patterns and institutional logics, but also contextual factors and crises may have an importance (Delmestri et al., 2015; Pollit,t 2008).

So what would the arguments and studies of convergence and divergence in reputation and branding lead us to expect of the Nordic universities we studied? First, we may expect university reputation profiles to reflect convergence and isomorphic features across countries, evidencing global pressure. Second, we can also expect variety in reputation management according to type of tasks/functions, size, age, and history - categorized into the following four types: 1) old, comprehensive universities; 2) specialized technical universities; 3) 'alternative or postwar universities' (Huisman et al., 2002 referred to these as '68-universities); 4) new/newly merged institutions. ${ }^{4}$ Comparing 2005 and 2015 reputation profiles, we would expect more isomorphic features in 2015 , but still also distinct variety among the universities.

\section{Main empirical features of reputation management in Nordic universities 2005 and 2015}

\section{Norway}

The overall picture is a lot of variety between types of tasks/functions, types of reputation symbols and universities. First, as expected, universities differ according to their historical presentations and accounts. The oldest universities use many performative, moral and

\footnotetext{
${ }^{4}$ See table 1.2. in chapter 1 for a detailed presentation of the Nordic universities included.
} 
professional reputation symbols. Their narratives relate to their history, something for which the two youngest universities obviously have less of a basis. Second, the pattern also varies with respect to strategies, with the oldest and largest paying most attention to performative and professional symbols, while the two newest and smallest universities score highest on the moral reputation symbols, which seem to show a 'compensatory' pattern.

Third, related to research symbols, all universities display prioritized areas, even though the largest, oldest and most research-intensive universities focus on this the most, in particular the Norwegian University of Science and Technology (NTNU). The moral symbols once again show a differentiated pattern. The smaller universities are playing it tough. Fourth, the moral symbols related to teaching and education are rather grand for most of the universities. The largest universities allude to broad professional educational symbols, while the smallest ones use regional symbols.

Fifth, the internal role-related symbols, like academic freedom, ethical guidelines and working environment are all of a typical moral character. Like the strategy category, the pattern here is differentiated with the two smallest universities scoring highest. Sixth, environmentally oriented symbols follow another and rather complex pattern, with both similarities and differences not closely linked to age or size. For most universities performative symbols allude to international collaboration in general and EU funding in particular.

If we compare types of headings and reputation symbols, two overall observations can be made. As expected, the highest scores among the three types of symbols are for moral symbols. Within this category, the smaller and newer universities score highest on symbols connected to strategy and academic freedom/ethical guidelines/working environment. The oldest and largest universities, on the other hand, score much higher in the categories of performative and professional symbols.

As we can see from figures 2.1 and 2.2, performance management is dynamic. There has been considerable changes in how the comprehensive universities and the specialized universities in our subsample use reputational symbols. All three have stepped up their use of performative, professional and moral symbols when they present themselves. The most noticeable change we see among the subsample of Norwegian universities is the increased emphasis on the performative dimension from 2005 to 2015, i.e. the same period as when the funding model of Norwegian universities was changed radically by introducing a strong elements of performance funding. We notice also that the three main universities have undergone very similar developments on all three reputation dimensions. Although the overall 
direction of change follows a similar track, the other Nordic country cases display more divergent practices (see below).

\section{Sweden}

First, the Swedish universities overall use rather few symbols related to the performative and professional dimensions of history. The main feature is that moral symbols are at the forefront. Second, related to strategy, the Swedish universities, like the Norwegian, overall score highest on moral symbols (three out of five score high). Third, related to research, performance symbols dominate, more so in the older than the younger universities.

Fourth, related to teaching, only moral symbols are mentioned, while the main websites have rather little performative and professional information. The youngest universities score highest, using nearly identical symbols in stressing that they are open and will create a learning environment with equal opportunities, regardless of gender, ethnic background, religious affiliation, functional level, gender identity or age.

Fifth, when it comes to the category of other internal features, the two youngest universities (UMU and LNU) score the highest overall. Symbols related to working environment dominate and are used by four out of the five Swedish universities: they stress, for example, the inspiring and attractive working environment, strong collegiality, nondiscrimination, environmental consciousness, and equality, respect and trust.

Sixth, concerning symbols related to environmental connections and collaborations, the performative aspects are the most important, and more so for the three oldest universities, which all stress international collaboration, networks and projects. Two of them also stress the most professional aspects of contacts with the environment, including the societal relevance of their professional knowledge. Few moral symbols are used in this category, but most often by the two youngest universities.

Comparing the different headings and types of reputational symbols, the moral symbols are used by far the most by Swedish universities, and most often related to the strategy category; within this category the two newest universities use such symbols more than others. The pattern is different concerning performative and in particular professional symbols, where the oldest three use such symbols more often.

The Swedish universities have followed similar developed as the Norwegian cases with one exception: the Swedish cases started out as the least morally oriented universities and ended up 10 years later scoring higher than any of the other country sub-samples. We also see that the technical university in the subsample of Swedish universities has really transformed its 
reputation management in the ten years from mid 2000s to 2015. In this period, the performative, professional and moral dimensions of these universities' activities have been boosted - and this concerns how this university presents its history, strategy, research activities and education. We notice also how KTH's representation to its external constituents is much more profiled in terms of performance.

\section{Denmark}

First, in presenting its history, the University of Copenhagen's (KU) tone is more professional than moral, combined with underscoring its track record as 'not only the oldest in the country but in Northern Europe'. The moral message is, on the other hand, strong both for the specialized Technical University of Denmark (DTU) - which talks about a 'new engineering era' - and the 'alternative' Roskilde University (RUC). Second, the use of moral reputation symbols is even more pronounced under the heading of strategy for several universities. KU, on the other hand, emphasises its research performance in its future strategies, highlighting its basic, cutting-edge research profile and its membership in the international league of top universities.

Third, under the heading of research, AU is the highest scorer on performative symbols actively displaying the whole panoply of indicators and positions in rankings. The performative and professional emphasis is strong and focused in the case of KU. Fourth, in presenting its teaching activities KU stands out in adhering strictly to symbols of professionalism, whereas AU as the other generalist university adds moral symbols. Fifth, under the heading environmental features, the old generalist university (KU) uses the scholarly value of international connections and being part of a community of likeminded, research-intensive universities as its core symbol. The other Danish universities refer to moral values that connect them with other constituents in society.

Comparing headings and types of symbols, KU has the strongest reputation profile, scoring high on all but one heading. Overall, KU's presentation is heavily weighted towards professional reputational symbols. The emphasis on quality, rationality and reason permeate the whole presentation. Of the four remaining Danish institutions, three score high on moral reputation symbols almost across the board.

The most interesting observation of how Danish universities have managed their reputation concerns the relatively stable way in which they present their performance (see figures 2.1 and 2.2). They started out at a higher level of emphasis on the performative dimension in 2005, but have been overtaken by the Norwegian and Swedish universities on 
this dimension over the recent 10 years. Whether this reflect changes in actual performance in research and education, we cannot assess with our data. We also note that the technical university (DTU) has actually reduced its emphasis on performance in this period - very much in contrast to the changes in reputation management we found in the case of the Swedish technical university.

\section{Finland}

The Finnish universities are striking in their overall parsimonious self-presentations. Most of the universities hardly attempt to underscore their teaching reputations on their websites; nor do they refer to other internal features. Here the University of Helsinki (UH) is the major exception. The sample also consists of two very recently merged institutions, and the findings show that despite their young age the reputation symbols used do not deviate much from the other universities in the Finnish sample, which primarily exhibit a mix of moral and professional symbols.

First, when the Finnish universities present their history, UH stands out from the others in its use of performative symbols - presenting itself in a traditional frame as the oldest and best university in Finland. Second, all universities use strong moral symbols in their presentation of strategies. UH sees itself as the most versatile institution, being a 'frontrunner', 'future-builder' and a 'society-shaper' aiming 'towards the top and out towards society', and offering an 'inspiring and caring environment'.

Under the research heading, all the Finnish cases predominantly use professional symbols - specifying their research collaborations and research priorities. Finnish universities highlight their research activities much more than their teaching, again with the exception of UH.

Overall, the Finnish universities also stand out in the extent to which they highlight their symbols (both moral and professional) in presenting their connections to a range of external actors. UH underlines its societal responsibility (academic quality is presented as the 'greatest gift to society'), offering 'unlimited opportunities for cooperation with organizations and industry'. The UEF highlights its professionalism, with staff participating in scientific organizations, expertise in getting external funding and its international cooperation as cornerstones, listing a number of international networks it participates in. Aalto University advertises its 'factories' as a main symbol of how it connects to its environment.

Across time, Finnish universities seem not to have changed their approach to managing their reputation in the same extent as the Swedish and Norwegian cases in the subsample. The 
reputation profile of the three universities in our subsample is fairly stable. In contrast to, most of the other Nordic universities in the subsample the University of Helsinki stand out both in 2005 and 2015 as the 'performing' university among the Finnish universities. That might reflect the hierarchy of the Finnish university system. With respect to how they emphasize their moral reputation, the Finish universities, however, do converge towards the common trend in the Nordic countries. This is the case for the universities as a group and for the universities of Helsinki, Tampere and Oulu individually.

\section{Main patterns of change}

Figure 2.2 summarizes the main findings as concerns the changes in reputation management in these universities over the last decade based on the subsample of three of the five universities per country included in the 2015 web-census. One main pattern is conspicuous - the webpages were in 2005 much more parsimonious in how they represent themselves compared to the content 10 years later. The changes in this respect are actually quite remarkable - the front pages of the universities website are much lighter when it comes to overall symbolic content. This is the main converging trend in our data. Universities in the Nordic region put more emphasis on managing their moral, professional and performative reputation through their websites. Moreover, the changes are also quite striking when it comes to presenting quantitative performance information. The Norwegian universities for instance have hardly any reference to performance on quantitative indicators in 2005. KU in Denmark have some emphasis on their performance in quantitative terms, but then mainly from the reference to their 'development contract' with their Ministry of Education. In addition, the reference to moral qualities is less pronounced than what we find for 2015 (see Table A.2.2 in appendix). Within these main patterns of change we see that national differences are relevant for understanding the dynamics of university reputation management. As we can see from Figure 2.1, the Norwegian and Swedish universities in our sample are significantly more change prone compared to their Finnish and Danish counterparts. This is especially evident in how they relate to the performative reputation.

Figure 2.1 Reputation management of Nordic universities by country. 2005 -2015 

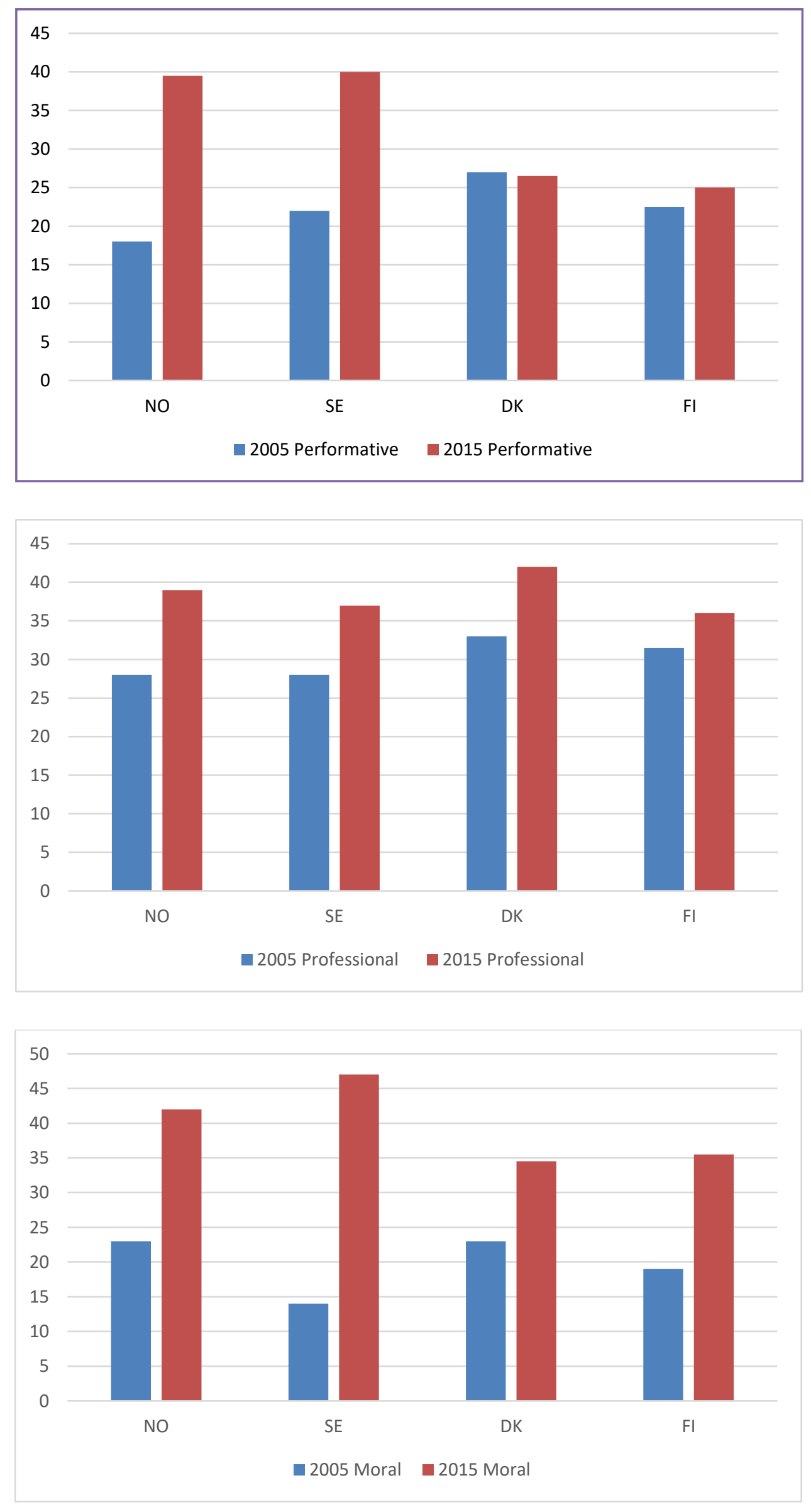
Figure 2.2 Change in reputation management of Nordic universities by institution. $2005-2015$
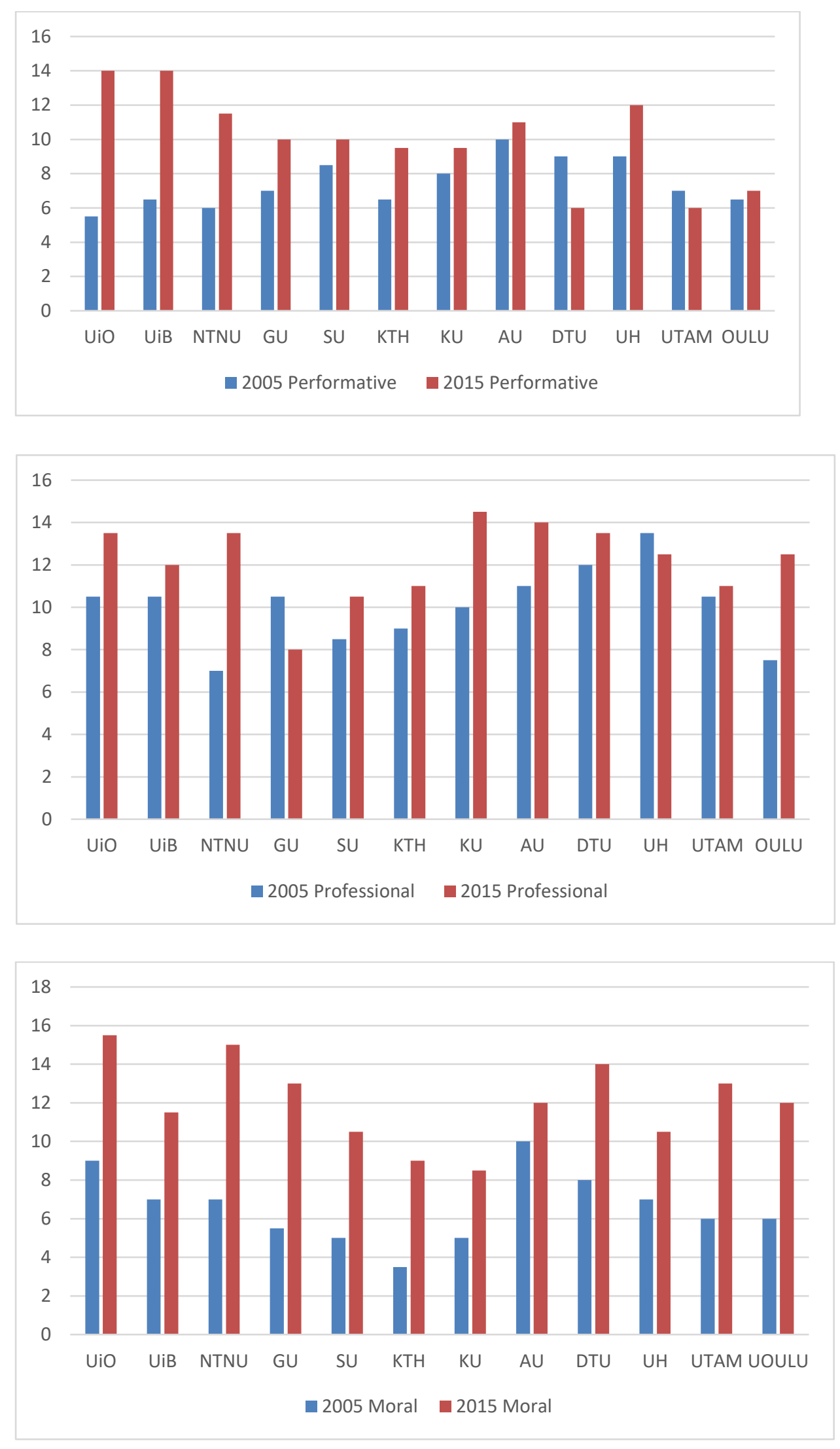


\section{Comparative analysis - among universities and over time.}

Our main results may be summarized and analyzed in the following points: Of the major categories of performative, moral and professional reputation management symbols (Carpenter $\&$ Krause, 2012), it is the moral symbols that are used the most, followed by the professional and performative ones. Overall, universities as public organizations in this Nordic sample place the highest premium on their moral reputation and being accountable as moral institutions to multiple audiences. One argument supporting this pattern is that universities as loosely coupled organizations with outcomes that are hard to measure will be prone to manipulation of symbols and social construction of reality (March \& Olsen, 1976). Moreover, from a culturalinstitutional perspective on reputation management, one could argue that such an emphasis reflects the fundamental understanding that the University (with a capital $U$ ) is a separate institutional sphere (Olsen, 2007) and a moral community representing a complex set of values and identities. Such institutions' reputations rest more on identifying and signaling what they are rather than what they do (performance).

Moreover, the fact that performative reputation symbols score lowest may reflect converging reputation management within the Nordic 'club' and the fact that the Nordic countries overall are egalitarian. Consequently, it is problematic for a university to boast about how good it is relative to others (Christensen, 2004). As illustrated, often the image building in this respect has to be rather abstract, such as the University of Oslo being 'allowed' by other universities to say it is among the 'leading European universities', but not the best one in Norway.

Second, in the category of moral symbols, it is the heading 'strategy, visions and goals' that scores highest, followed by symbols directed towards the environment. This former heading is definitely also prone to using reputation symbols, because it is loose and ambiguous. As Brunsson (1989) would argue; strategies, plans and goals belong to the world of 'talk', where intentions to act are presented to increase the legitimacy of leaders, but not necessarily acted upon. The high score of symbols directed towards the environment may indicate a rather strong focus on social embeddedness for the universities, and possibly also a focus on social accountability, i.e. an increasing pressure to account to the public at large for university activities, including those related to external stakeholders (Ramirez \& Christensen, 2013).

Third, under the heading of professional reputation, symbols related to history, strategies and research score highest, while teaching and other internal factors score low. The 
former factors are in some ways connected, because reputation management tends to emphasize a proud professional history and current high professional standards, but also professional strategies and plans for the future. The rather low score for teaching activities may indicate both the absence of tuition fees and the rather low status of teaching at Nordic universities, partly reflecting a historical path, but also the pressure from the mass university and the emphasis on academic output in recruiting academic staff (Christensen et al., 2014). It is also interesting that internal features, academic freedom, ethical guidelines and working environment apparently have very little to do with professional symbols.

Fourth, related to the heading of performative symbols, research- and environmentrelated symbols score highest, while teaching and other internal performance score the lowest. Research achievements are emphasized, as is collaboration with stakeholders nationally and internationally. Teaching reputation is not 'hard currency' for individual academics and academic groups. Government funding models in the Nordic countries, on the other hand, give strong incentives for effective credit point production. There are also readily available output measures that Nordic universities could use in their presentations. It is therefore surprising that the institutions studied keep such a low profile when it comes to performative symbols in the area of teaching and learning. This pattern of performance management also indicates that in this area universities do not manage their image as teaching institutions by providing performance-oriented market information to the student market.

Table 2.1 Types of universities and type of reputation symbols 2015

\begin{tabular}{lccccc}
\hline & \multicolumn{5}{c}{ Type of institution } \\
\cline { 2 - 6 } $\begin{array}{l}\text { Type of } \\
\text { reputation } \\
\text { symbol }\end{array}$ & Old General & General & Specialized & $\begin{array}{c}\text { '68- } \\
\text { universities' }\end{array}$ & Young \\
\hline Performative & High & High/medium & High & Low & Low \\
Moral & Medium & Medium & High & High/medium & Medium \\
Professional & Medium & Medium & High & Low & Low \\
Overall score & Medium & Medium & High & Low & Low \\
\hline
\end{tabular}

Table 2.1 returns to the categorization made of the universities studied. What is the relationship between the use of reputation symbols and type of university? Overall, the specialized universities make the most intensive use of a variety of reputation symbols, while the typical 
'68-universities' and the young universities score low and the 'old general' and 'general' universities score medium. There could be many reasons for this pattern. Specialized universities are primarily technical/technological universities focused on natural sciences. This presumably gives them an edge both with respect to measurable performance, including symbolic accounts of their history, alluding to symbols of professional education/research and moral symbols related to society and the economy at large. This reflects the advantages of the narrow focus and unique profile of such universities (Wæraas and Byrkjeflot 2012).

When it comes to the use of reputation symbols, the ' 68 universities' and the young universities have a number of disadvantages They can not boast a long history or a strong performance record, and they do not have a strong professional record either. So instead they try to compensate by using moral reputation symbols, which are less connected to history, performance and professional knowledge. Some of them actively present their 'newness' as an innovative 'break with the past' to external audiences and to legitimize internal radical action (Aula \& Tienari, 2011). Since these universities have more of a social science profile and a younger staff overall, one would expect this to give them an edge in manipulating symbols. One of the challenges of course is that an exaggerated use risks losing legitimacy. If you're a rather small regional university talking about global excellence in many respects, there could be a disjoint between talk and action (Brunsson, 1989).

The general universities, whether old or not, have an advantage with respect to performative symbols, because they have a lot of resources and are educating a range of professional groups. But they are also heterogeneous, which may make it difficult to present a consistent and unique image (Wæraas \& Byrkjeflot, 2012). On the other hand, they may also potentially use 'bridging' symbols with a broad profile (Røvik, 2002). In this perspective it is interesting that they score lower than the specialized universities on using moral reputation symbols.

\section{Change over time}

The analysis of patterns of change in reputation management shows clearly how the approach to managing universities' reputation through their websites has changed drastically - the webpages seem to have become significantly more 'symbolically laden' over the past decade. Overall, the performative, moral and professional qualities are much more profiled on these universities' websites in 2015 compared to 2005. Clearly, the webpages have become the main face through which the universities communicate their mission and vision and their professional qualities to multiple audiences. The quantitative performative symbols seem to be 
in particular absent from these universities 'presentation of self' 10 years ago. This corresponds well to overall changes in these institutions environment the past decade the performance funding has been introduced with full force in the Nordic countries and international rankings and impact measurements have proliferated on the global higher education scene. We notice however the relevance of national systemic differences also for understanding the dynamics of reputation management, as we have seen in the differences between the Finnish and the Danish universities on the one hand the Norwegian and Swedish universities on the other. We cannot with our data see whether differences between the new and 68-types class of universities and the other comprehensive and old universities is the result of diverging change trajectories or reflect more deep rooted path dependencies of these institutions. Furthermore, the changes in the audiences that universities address comes across as an important dimension to pursue - in particular the change in orientation towards an international student, research and 'peer' audience might indicate a fundamental shift in the way the these organizations manage their reputation. This includes how international branding have increasingly become an element in managing domestic reputation and hence also the power base of these institutions.

\section{Conclusion}

Wærnes and Byrkjeflot (2012, p.193-200) emphasize five potential problems related to the management of reputation in public organizations. The politics problem relates to changing political leadership and limited discretion; the consistency problem alludes to balancing diverse interests in heterogeneous organizations; the charisma problem stresses how to overcome bureaucracy-bashing and make public institutions look attractive; the uniqueness problem focuses on the limits of standing out as unique in an age of standardization and rationalization; and the excellence problem emphasizes how easy it is culturally and in other ways to portray a public organization as excellent.

These problems may give insight into why specialized universities overall score highest on the three reputation management dimensions, while the general universities score medium and the '68 universities' and the younger ones score lowest. Technological universities are probably less vulnerable to political and policy change than other types of universities. Normally they have fewer consistency, charisma, uniqueness and excellence problems, because they have a narrow profile in the natural sciences. At the other extreme, the '68universities' and the young universities are much more vulnerable to shifting political preconditions when building up their organizations and try to project a consistent, charismatic and unique excellence profile, partly also because of regional pressure from different 
stakeholders. This is clearly illustrated by the controversy over how to brand the University of Troms $\varnothing$ as an Arctic university (Wærness \& Solbakk, 2009).

The general universities have an advantage relative to the younger ones related to history and performance, but may struggle more than specialized universities to project a consistent, charismatic and unique image. And the excellence potential may be more difficult to play out in a Nordic egalitarian culture, as seen with the problem of branding the University of Oslo as the best in Norway.

Our study is not a process study, so we do not know whether the universities involved have experienced periods of crisis influencing the use of reputation symbols, or whether this is a snapshot of everyday life, but it is more likely to be the latter. Whether our reputation data actually reflect decisions already taken or rather aspirations - 'who we pretend to be' - is difficult to say without deeper process data.

\section{References}

Aula, H. M., \& Tienari, T. (2011). Becoming "world-class"? Reputation-building in a university merger. Critical perspectives on international business, 7(1), 7-29.

Bleiklie, I., Enders, J., Lepori, B, \& Musselin, C. (2011). New Public Management, Network Governance and university as a changing professional organization. In T. Christensen \& P. Lægreid (Eds.). The Ashgate Companion to New Public Management, Farnham, IK: Ashgate.

Brunsson, N. (1989). The Organization of Hypocrisy. Talk, Decisions and Actions in Organizations. Chichester: Wiley.

Carpenter, D., \& Krause, G.A. (2012). Reputation and Public Administration. Public Administration Review, 72:26-32t.schillemans@uu.nl.

Christensen, T. (2004). Modern state reforms. In K. Heidar (Ed.). Nordic Politics. Comparative Perspectives. Oslo: Universitetsforlaget.

Christensen, T., Gornitzka, Å., \& Maassen, P. (2014). Global Pressures and National Cultures: A Nordic University Template? In P. Mattei (Ed.). University Adaptation in Difficult Economic Times, Oxford University Press.

Czarniawska, B., \& Sevón, G. (Eds.)(1996). Translating Organizational Change. Berlin: De Gruyter.

Delmestri, G., Oberg, A., \& Drori, G. (2015). The unbearable lightness of university branding. International Studies of Management \& Organization, 45, 121-136. 
Gornitzka, A., \& Maassen, P. (2000). Hybrid steering approaches with respect to European higher education. Higher Education Policy, 13(3), 267-285.

Gornitzka, А., \& Maassen, P. (2011). University governance reforms, global scripts and the 'Nordic Model'. Accounting for policy change? In J. Schmid, K. Amos, J. Schrader \& A. Thiel (Eds.). Welten der Bildung? Vergleichende Analysen von Bildungspolitik und Bildungssystemen. Baden-Baden: Nomos Verlag.

Greve, C., Lægreid,P. \& Rykkja, L.H. (2016). The Nordic Model Revisited: Active Reformers and High Performing Public Administrations. In C.Greve, P.Lægreid \& L.H.Rykkja (Eds.), Nordic Administrative Reforms. Lessons for Public Management. London: Palgrave Macmillan.

Huisman, J., Norgård, J.D., Rasmussen, J.G., \& Stensaker, B. (2002). 'Alternative' Universities Revisited: A Study of the Distinctiveness of Universities Established in the Spirit of 1968. Tertiary Education and Management, 8(4), 316-332.

Jungblut, J. (2015). Bringing political parties into the picture: a two-dimensional analytical framework for higher education policy. Higher Education, 69(5): 867-882.

March, J.G., \& Olsen, J.P. (1976). Ambiguity and Choice in Organizations. Bergen: Universitetsforlaget.

Morphew, C. C., \& Hartley, M. (2006). Mission statements: A thematic analysis of rhetoric across institutional type. Journal of Higher Education, 77, 456-471.

Norden (2013). Tuition fees for international students - Nordic practice. TemaNord 2013:516, Copenhagen: The Nordic Council of Ministers.

Olsen, J.P. (2007). The Institutional Dynamics of the European University. P. Maassen \& J.P. Olsen (Eds.). University Dynamics and European Integration. Dordrecht: Springer.

Ramirez, F.O., \& Christensen, T. (2013). The formalization of the university: rules, roots, and routes'. Higher Education, 65(6), 695-708.

Røvik, K.A. (2002). The Secrets of the Winners: Management Ideas That Flow. In K. SahlinAndersson \& L. Engwall (Eds.). The Expansion of Management Knowledge-Carriers, Flows and Sources. Stanford. CA: Stanford University Press.

Wæraas, A., \& Byrkjeflot, H. (2012). Public Sector Organizations and Reputation Management: Five Problems. International Public Management Journal, 15(2): 186206.

Wæraas, A., \& Solbakk, M.N. (2009). Defining the essence of university: lessons from higher education branding. Higher Education, 57, 449-462. 
Appendix.

Insert tables A.2.1. and A.2.2 about here 